\title{
OS PARADIGMAS \\ EPISTEMOLÓGICOS QUE \\ SUBJAZEM ÀS DECISÕES \\ JUDICIAIS
}

\section{Telga Persivo Pontes de Andrade}

aluna do de Direito da FA7.

telgapersivo@yahoo.com.br

Sumário: Introdução. 1. O evoluir paradigmático e as decisões judiciais. 2. Decisões judiciais e o giro ontológico-linguístico. Considerações finais. Referências

Resumo: Este artigo aborda os problemas filosóficos conexos à teoria do direito contemporâneo e sua hermenêutica. Objetivamos desvelar os paradigmas epistemológicos que povoam o imaginário de nossos magistrados e alicerçam suas decisões. Através de um procedimento metodológico de revisão bibliográfica, intentamos elencar e conceituar cada um desses paradigmas; verificar qual deles predomina no imaginário de nossos juízes e subjaz às suas decisões, de acordo com a literatura atual. Compreender se ao exercer a atividade concretizadora da lei, os juízes perseguem, simplesmente, a verdade unívoca da lei, decidem conforme suas consciências ou entendem-se seres históricos, fruto da intersubjetividade constitutiva, que lhes confere o existencial heideggeriano pré-compreensão, com fulcro na linguagem. Inteligir, por fim, como a escolha de um ou outro desses paradigmas pode suscitar decisões controversas, e em decorrência gerar insegurança jurídica.

Palavras-chave: Paradigma da consciência. Paradigma da intersubjetividade. Giro ontológico-linguístico. Existencial heideggeriano pré-compreensão. Decisões judiciais.

\section{INTRODUÇÃO}

A maneira como um juiz interpreta uma determinada norma jurídica depende constitutivamente de sua visão e interação com o mundo; poucos são os que ainda defendem a possibilidade de um magistrado conseguir a neutralidade jurídica, mítica, defendida pelo positivismo.

Compreender e interpretar são indissociáveis, como indissociável é o direito no contexto sócio-histórico e cultural da sociedade sob sua égide; o direito é um construto social, e a norma aplicável ao caso concreto, por sua vez 
depende de como, consciente ou inconscientemente, o processo de conhecimento é elaborado na mente do juiz.

Em decorrência dessa imbricação essencial, as sentenças judiciais são reflexo dos paradigmas epistemológicos, que desde a Antiguidade buscam explicar como se processa o conhecimento na mente humana.

Três são esses paradigmas, que, conquanto surgidos em épocas distintas, convivem e subsistem ainda numa feroz contenda até nossos dias no âmbito jurídico.

O primeiro desses paradigmas é o objetivismo ou realismo filosófico, para o qual o juiz é um mero subsunsor de normas, que deve perseguir o sentido unívoco da norma jurídica; para essa concepção o texto legal é possuidor de uma objetividade intrínseca e sobrepõe-se ao intérprete.

Para o segundo, paradigma da consciência, o Direito é aquilo que o intérprete quer que seja e as decisões judiciais são tomadas de acordo com o que pensam e creem os juízes.

O terceiro é o paradigma da intersubjetividade, oriundo da revolução linguístico-filosófica, que eclodiu no século XX, tendo como mentor o filósofo Martin Heidegger e, um importante seguidor, Hans Gadamer. Para essa concepção o operador do direito (seja ele autor da lei ou quem a aplica), já possui, como existenciale, um modo de ser constitutivo, uma pré-compreensão do mundo, e é na linguagem que se dá o sentido da norma e não na consciência do intérprete. É a nossa pré-compreensão do mundo, no qual somos projetados que determina o sentido do texto.

Este último é o paradigma que alicerça o Estado Democrático de Direito, o qual propugna pelo social, pelo coletivo, pelo intersubjetivo. Ele é fruto das duas grandes revoluções experienciadas pela filosofia e pelo direito no decorrer do século XX: o constitucionalismo e o giro linguístico-ontológico.

Esse é um tema extremamente atual, que discute a crise pela qual atravessa o direito não somente no âmbito de sua operacionalidade, bem como no domínio do ensino-aprendizagem do mesmo nas Instituições de Ensino Superior de nosso País.

O Direito, após a dicotomia introduzida pela metafísica, dissociou-se em teoria/prática, norma/fato, texto/norma, questão de fato/questão de direito sendo levado a um excessivo instrumentalismo, dito de outra forma, ele deixou de ser intuído como ciência da compreensão, para ser utilizado como um instrumento, manipulável pelo operador do direito.

No âmbito educacional, o ensino do Direito abandonou o método de estudo de casos de Christopher Langdell, do qual era pioneiro (SCHÖN, 2000, p. 23). Com isso, o direito distanciou-se cada vez mais dos anseios sociais, não 
conseguindo a efetividade necessária para dirimir as contendas jurídicas dos membros da sociedade sob sua égide, cindindo agora validade e legitimidade.

Nosso escopo, nesse artigo, é, através de um procedimento metodológico de revisão bibliográfica, elencar e conceituar cada um desses paradigmas; verificar qual deles predomina no imaginário de nossos juízes, de acordo com a literatura atual, e intentar, por fim, esclarecer a forma como a escolha de um ou outro desses paradigmas pode suscitar decisões controversas, e em decorrência gerar insegurança jurídica.

\section{Evoluir Paradigmático e as Decisões Judiciais}

O Direito encontra-se inserto nas ciências humanas, mais especificamente numa espécie desse gênero, as ciências sociais, cuja característica basilar é entender que, do ponto de vista metodológico, seu objeto de estudo é socialmente condicionado, ou seja, seu objeto, deslocado do contexto das inter-relações sociais, torna-se incompreensível (DEMO, 1987, p.13-14).

A construção do sentido da lei, a maneira como o juiz interpreta a norma está intrinsecamente ligada ao modo de ser e compreender o mundo desse operador de direito.

Silva (2000, p.25), com muita propriedade, nos fala sobre a conexão entre interpretação, sentido do texto, linguagem e hermenêutica:

Nos procedimentos de interpretação ocorrem a concretização do sentido do texto. Este aspecto comunicativo da linguagem é de grande importância para o diálogo hermenêutico, daí a relação fundamental entre linguística e compreensão para o entendimento do fenômeno hermenêutico.

Esse interpretar e compreender o mundo, ou seja, o contexto no qual está ínsita a norma jurídica aplicável ao caso concreto, por sua vez, depende de como, consciente ou inconscientemente, o processo de conhecimento é elaborado na mente do juiz, quando este persegue a vontade da lei, a verdade nela oculta ou quando já possuidor de uma pré-compreensão constitutiva busca prolatar uma decisão mais adequada à Constituição.

Segundo Silva (2000, p. 45) "como teoria da interpretação, cabe à hermenêutica a tarefa de fazer compreender o sentido do assunto [....]", e esse compreender está ligado à teoria do conhecimento.

Para Streck (2010, p.14) a crise que ainda hoje assola a hermenêutica jurídica é uma crise intrinsecamente ligada à crise da teoria do conhecimento, portanto desses paradigmas. 
Na edificação do repertório conceitual da Ciência Jurídica brasileira manifesta-se a influência de três paradigmas epistemológicos: o objetivismo, o subjetivismo e o intersubjetivismo.

Para o objetivismo ou realismo filosófico, o juiz é um mero subsunsor de normas, ao qual compete descobrir o sentido unívoco da norma jurídica; para essa concepção o ato de interpretar é produto da objetividade plenipotenciária do texto, porque a objetividade do mesmo sobrepõe-se ao intérprete; a lei expressa no texto tem vida própria, a lei vale tudo.

A interpretação do direito, intimamente conectada à epistemologia, foi durante séculos caracterizada pelo predomínio do esquema sujeito-objeto preconizado por esse paradigma objetivista e o positivismo foi o local privilegiado dessa relação.

As teorias alicerçadas nesse esquema sujeito-objeto trabalham com o dualismo metafísico, que cinde teoria/prática, texto/norma, questão de fato/ questão de direito, interpretação/aplicação, dentre outras rupturas e culmina por rescindir validade/legitimidade (STRECK, 2009a, p. 415-420).

Essas teorias reportam-nos a Aristóteles e sua razão prática, a qual divide a filosofia grega em filosofia prática, que indaga pelo certo e pelo errado, e filosofia teórica, que pergunta pela verdade ou pela falsidade.

$\mathrm{Na}$ era moderna Kant ressuscita esse dualismo, razão prática/ razão teórica, em suas obras e introduz um terceiro elemento, qual seja o sujeito transcendente e seu solipsismo (sujeito solipsista, Selbstsüchtiger); de acordo com a razão teórica pura kantiana, o direito seria produto desse sujeito do conhecimento, que o avaliaria conforme critérios emanados de uma lógica formal rígida (STRECK, 2009a, p.417).

Sobre a nocividade dessa dicotomia kantiana, que persiste ainda hodiernamente no âmbito do direito pátrio, preleciona Ovídio Batista:

A separação entre "direito" e "fato", inspirada nos dois mundos kantianos, o mundo do ser e do dever ser, que deita raízes no racionalismo dos filósofos do século XVII, permanece intocada na doutrina contemporânea, mesmo que ninguém tenha dúvida de que o Direito, como ciência da compreensão, exista no "fato" hermeneuticamente interpretado (SILVA, 2004 , p.36).

O positivismo finca seus pilares nesse dualismo metafísico e, no âmbito do direito, objetivando a criação de um método e de um objeto seguro para a produção do conhecimento, separa a validade das normas jurídicas (ínsitas na Teoria do Direito), de sua legitimidade (insertas na Teoria Política); ou seja, a teoria do direito, como se tivesse uma objetividade autônoma, afasta-se da lide, dos fatos sociais, dissocia-se da realidade fática, enfim separa o ente do seu indissociável ser. 
Esse movimento filosófico foi influenciado pelas ciências lógicas, e esse fato levou o direito a desenvolver sua racionalidade através da dedução e do silogismo. Ao legislador competia criar regras gerais e abstratas, sendo proibido ao aplicador do direito interpretá-las, cabendo-lhe apenas perseguir o sentido unívoco da lei, pois a objetividade do texto (CARNEIRO, 2011, p. 31-35) sobrepõe-se ao aplicador, garantindo, por conseguinte, a previsibilidade e segurança jurídica.

Descartes, no século XVII, e Leibniz, no século XVIII, propagaram essa pretensa universalidade epistemológica das ciências exatas às demais ciências. Para Descartes o conhecimento das coisas far-se-ia fragmentando-se o objeto em partes menores, e num movimento deducionista, das partes para o todo, chegar-se-ia ao conhecimento pleno (DESCARTES, 2000, p. 49).

No âmbito jurídico essa teoria far-se-ia através da aplicação dedutiva e silogística da lei, a partir da qual, sem inovar ou arguir qualquer juízo de valor, o julgador poderia decidir as lides, convertendo o direito numa ciência pura, isenta de qualquer influência de outros ramos do conhecimento; com isso o direito ganharia em segurança, pois a validade do direito criado pelo juiz repousaria na certeza da lei, criada pelo legislador. Esse paradigma positivista predomina durante toda a metade do século XX (STRECK, 2011, online).

Com a modernidade e o Iluminismo, dá-se a superação do objetivismo e exsurge o paradigma da subjetividade ou paradigma epistemológico da filosofia da consciência, e o mundo passa a ser agora explicitado através da razão (STRECK, 2010, p.13).

Nesse contexto paradigmático da relação sujeito/objeto, o sujeito cognoscente precisa fazer uma operação mental de sua subjetividade com o objeto a conhecer, ou seja, efetuar a subsunção entre o conceito fático e o conceito normativo (STRECK, 2009a, p.230-231).

Para os adeptos do paradigma da consciência as decisões judiciais são tomadas de acordo com o que pensam os juízes, com suas crenças; dizer a lei, decidir é uma atitude solipsista do intérprete. Esse pensar encontra-se ainda hoje arraigado no imaginário de nossos juristas e ministros do nosso judiciário, conforme se depreende do discurso do Ministro do Supremo Tribunal da Justiça, Luis Felipe Salomão: “ [....] Justiça que emana exclusivamente de nossa cons-ciência, sem apego obsessivo à letra fria da lei. [....]" (STRECK, 2010, p.24).

Perfilado com o teor do voto do ministro Humberto Gomes de Barros, do Superior Tribunal de Justiça:

Não me importo com os doutrinadores. Enquanto for Ministro do Superior Tribunal de Justiça, assumo a autoridade da minha jurisdição. [....] Decido, porém, conforme a minha consciência. Precisamos estabelecer nossa autoridade intelectual, para que este Tribunal seja respeitado. É preciso consolidar o enten- 
dimento de que os srs. Ministros Francisco Peçanha Martins e Humberto Gomes de Barros decidem assim porque pensam assim. E o STJ decide assim porque a maioria de seus integrantes pensa como esses ministros. Esse é o pensamento do Superior Tribunal de Justiça, e a doutrina que se amolde a ele. É fundamental expressarmos o que somos. Ninguém nos dá lições. Não somos aprendizes de ninguém. (STRECK, 2010, p.25).

Será que o Direito é, realmente, aquilo que o intérprete quer que ele seja, ou é o que está estatuído na Constituição, a qual representa (ou pelo menos deveria representar) os valores e ideais de nossa sociedade? No Estado Democrático de Direito nossa consciência não deveria ser a Constituição Federal? Depois de uma intensa luta pela democracia e por direitos fundamentais estatuídos numa Carta Magna, o próprio resultado do processo dependerá exclusivamente do que a consciência do juiz indicar? E, ao recorrer a uma segunda instância, passará a depender da consciência de outro (ou outros) juiz(es)? Não há limitação de poder na democracia? (STRECK, 2010, p.26).

A Justiça não pode ficar refém da opinião pessoal que cada Juiz ou Ministro tenha a respeito da lei ou fenômenos sociais, pois o sentido dessas leis e desses fenômenos são produtos de uma intersubjetividade, e não de um indivíduo isolado, solipsista; esses critérios intersubjetivos estão estatuídos na Constituição (STRECK, 2010, p.26).

\section{Decisões Judiciais e o Giro Ontológico-Linguístico}

O Direito sob a égide do Estado Democrático de Direito não é indiferente às razões pelas quais um juiz ou um tribunal toma suas decisões. $\mathrm{O}$ direito sob o paradigma do Estado Democrático de Direito cobra reflexões acerca dos paradigmas que informam a própria jurisdição constitucional (CATTONI, 2004, p.51). Alinhado a esse pensar assevera Streck:

O Estado Democrático de Direito é um novo paradigma porque foi engendrada, no campo do direito constitucional e da ciência política, uma nova legitimidade, no interior da qual o Direito assume a tarefa de transformação [....] (2004, p.165).

Com o século $\mathrm{XX}$, a partir do que passou a ser denominado giro linguístico, ou ainda filosofia da linguagem, a teoria do conhecimento é marcada pela ruptura da estrutura cognitiva sujeito/objeto, que alicerçou a epistemologia metafísica durante dois milênios, e nova estrutura cognitiva se impõe, a sujeito/ sujeito (CARNEIRO, 2011, p.71); o ato de conhecer transfere-se para o âmbito da linguagem; é na linguagem (e não na consciência do sujeito solipsista), que se dá o sentido das coisas. 
A linguagem é nossa condição de estarmos no mundo, e segundo Stein (1997, p.86), o conhecer, o acesso a algo, somente ocorre pela mediação do significado e do sentido.

Nesse período em que o Estado Democrático de Direito está alicerçado no intersubjetivismo, o paradigma que insurge é o linguístico-filosófico, que revolucionou o século XX, chamado paradigma da intersubjetividade, o qual tem em Martin Heidegger seu precursor.

No âmbito da jurisdição constitucional, fundada na fenomenologia hermenêutica, e para essa concepção, em exercendo a atividade jurídica, o operador do direito (seja ele autor da lei ou quem a aplica), já possui, como existenciale, um modo de ser constitutivo, uma pré-compreensão da Constituição, uma compreensão antecipada, e é na linguagem que se dá o sentido da norma e não na consciência do intérprete.

É a nossa pré-compreensão do mundo, no qual somos projetados que determina o sentido do texto; explicitando melhor, sob os auspícios dessa concepção, em exercitando o direito, a Constituição deixa de ser algo estático, pontual, ocasional durante o ato interpretativo, para ser parte dinâmica e constitutiva do ato de interpretar (STRECK, 2010, p.18).

Conforme afirma Carneiro (2011, p. 63), em Heidegger:

O que se antecipa não está no sujeito - na consciência - mas sim na linguagem à qual o sujeito; uma linguagem que é a "morada do ser' e, como tal, condição de possibilidade para a compreensão.

É essa dinâmica, esse movimento que faz com que o direito acompanhe o evoluir histórico da sociedade e, em corolário, do Estado, propiciando-nos um Direito vivo, inserto nos anseios e valores propugnados pelo cidadão.

O motivo de esse paradigma ter seu fulcro na linguagem, quem nos pode explicar é Gadamer; para esse filósofo, a linguagem tem por função elaborar, de forma constante, a síntese entre o horizonte do passado e do presente; e nós nos compreendemos uns aos outros, à proporção que conversamos e usamos as palavras que nos fazem compartilhar as coisas às quais essas palavras se referem. Continua esclarecendo que:

[...] apesar de termos todos uma linguagem diferente, podemos nos compreender além do limite dos indivíduos, dos povos, e dos tempos. [....] as coisas, sobre que falamos, apresentam-se diante de nós como algo comum, quando falamos sobre elas. O que entendemos por verdade - revelação, desocultação das coisas - tem, portanto, sua própria temporalidade e historicidade (2002, p. 71). 
Não esqueçamos que o direito é linguagem (STRECK, 2009b, p.186) constituída por signos linguísticos verbais (v.g. decisões, mandados, normas jurídicas etc.) e não-verbais, como a sinalização de trânsito, dentre outras (SANTAELLA, 2007, p. 09-13).

É na linguagem, que a Constituição, nesse contexto hermenêutico está, estejamos ou não cônscios desse fato, presente em todos os atos praticados no exercício da nossa prática jurídica cotidiana.

A Constituição está intrinsecamente imbricada nesse vivenciar jurídico habitual e a Ela recorremos e Dela extraímos sentidos.

Por conseguinte, cada um de nós já traz consigo como um modo fundamental de ser, uma pré-compreensão da Constituição, um existenciale.

A Filosofia e o Direito no século XX sofreram duas grandes revoluções segundo Streck (STRECK, 2011, online), o constitucionalismo e o giro linguístico-ontológico.

Para a epistemologia superar o pensamento metafísico os filósofos levaram mais de dois milênios. De início no paradigma da metafísica clássica os sentidos emanavam das coisas, em sua essência; na metafísica moderna na mente do sujeito solipsista, na consciência do sujeito cognoscente; na pós-metafísica passam a ser acessados na e pela linguagem.

A dogmática jurídica, inobstante, não aderiu à ruptura paradigmática nem no ensino dos cursos de Direito, nem na práxis, levando a uma ineficácia da Constituição. Indiferente a toda inovação, proporcionada por esse novo paradigma, mais adequado às relações sociais preconizadas pela constitucionalização e pelos ditames do Estado Democrático de Direito, as decisões judiciais avaliadas em regiões diversas de nosso País apontam para uma total discrepância entre o teor delas e os anseios sociais; alicerçado em Warat nos é possível intuir que o imaginário jurídico é apoiado num realismo das significações, onde a razão é construída de forma abstrata e totalmente dissociada dos elementos sócio-históricos, que permeiam as relações sociais dos sujeitos das lides julgadas (WARAT, 1995, p.116); ou seja, o exercício do direito prescinde do contexto social, dos fatos da vida real.

$\mathrm{O}$ direito como construto social, oriundo da cultura do povo que rege, deve acompanhá-lo em suas transformações, para que possa regular a contento a vida em comunidade.

Em persistindo na manutenção de paradigmas ultrapassados (ainda reféns do positivismo jurídico e da filosofia da consciência) e inadequados à complexidade das relações sociais atuais, o Estado não consegue efetivar os ditames constitucionais e dirimir a contento as lides sociais.

Este é o estado da arte do modus paradigmático de julgar, que perpassa o imaginário jurídico brasileiro. 


\section{Considerações Finais}

Três paradigmas epistemológicos influenciam de forma substancial o exercício do Direito no Brasil: o objetivista, o subjetivista e o intersubjetivista.

Coexistem ainda, no imaginário de nossos juízes, similares aos arquétipos de Jung, os paradigmas objetivista e subjetivista, com predomínio desse último.

Esses paradigmas, embasados nos quais nossos magistrados persistem sentenciando, já deveriam ter sido postergados, em especial o subjetivista, por permitir uma discricionariedade incompatível com o Regime Democrático albergado pela Constituição Federal de 1988.

O paradigma preponderante é incompatível com o Estado Democrático de Direito, por conseguinte, não consegue efetivar os ditames constitucionais, em decorrência de ser oriundo de uma concepção muito individualista, extremamente distanciada dos direitos transindividuais coletivos hoje albergados pela nossa Constituição.

No exercício da atividade concretizadora da lei, os juízes decidem fundados em suas consciências e não se entendem ainda produto da intersubjetividade, com fulcro na linguagem. Em consequência disso, muitas vezes, tais decisões, alicerçadas no paradigma da subjetividade, não refletem aquela deliberação mais adequada à Constituição (por serem proferidas conforme a cons-ciência do intérprete, o qual somente após decidir, tenta fundamentar sua decisão, conformando-a às normas, ou seja, forçando uma interpretação que a valide).

Em decidindo de acordo com suas consciências, essas decisões tornam-se contraditórias, em consonância com o magistrado que as prolata e, consequentemente, fonte de insegurança jurídica e incompatível o Estado Democrático de Direito.

O direito é uma ciência prática, por conseguinte não pode se alicerçar num paradigma que afastou das discussões jurídicas as questões concretas da sociedade.

\section{REFERÊNCIAS}

CARNEIRO, Wálber Araújo. Hermenêutica jurídica heterorreflexiva: uma teoria dialógica do direito. Porto Alegre, Livraria do Advogado, 2011.

CATTONI, Marcelo. Jurisdição e hermenêutica constitucional. Belo Horizonte: Mandamentos, 2004.

DEMO, Pedro. Introdução à metodologia da ciência. São Paulo: Atlas, 1991.

DESCARTES, René. Discurso do método. In: Os pensadores. São Paulo: Editora Nova Cultural, 2000. 
GADAMER, Hans-Georg. Verdade e Método. Traços fundamentais de uma hermenêutica filosófica. Petrópolis: Vozes. 1999.

SANTAELLA, Lúcia. O que é semiótica. São Paulo: Brasiliense, 2007.

SCHÖN, Donald A. Educando o profissional reflexivo: um novo design para o ensino e a aprendizagem. Porto Alegre: Artes Médicas Sul, 2000.

SILVA, Ovídio Araújo Baptista da. Processo e Ideologia: o paradigma racionalista. Rio de Janeiro: Forense, 2004.

SILVA, Susane Alflen da. Hermenêutica jurídica e concretização judicial. Porto Alegre: Fabris, 2000.

STEIN, Ernildo. A caminho de uma fundamentação pós-metafísica. Porto Alegre: Edipucrs, 1997.

STRECK, Lenio Luiz. Jurisdição constitucional e hermenêutica: uma nova crítica do direito. 2. ed.Rio de Janeiro: Forense, 2004.

Verdade e consenso. 3.ed.Rio de Janeiro: Lumen, 2009a.

Hermenêutica jurídica e(m) crise: uma exploração hermenêutica da construção do Direito. 8. ed. Porto Alegre: Livraria do Advogado, $2009 \mathrm{~b}$.

.O que é isto - decido conforme minha consciência? Porto Alegre, Livraria do Advogado, 2010.

Acesso em 09/05/2011.

. Crise de paradigmas. Disponível em: http://leniostreck.com.br.

. Hermenêutica e ensino jurídico em terra brasilis. Disponível em: http://leniostreck.com.br. Acesso em 09/05/2011.

WARAT, Luis Alberto. Introdução geral ao direito: a epistemologia jurídica da modernidade. Porto Alegre: Fabris, 1995.

\section{EPISTEMOLOGICAL PARADIGMS UNDERLYING LEGAL DECISIONS}

Abstract: This article approaches philosophical problems related to contemporary legal theory and hermeneutics. Our objective is to unveil the epistemological paradigms that fill the imaginary of our magistrates and serve as basis for their decisions.

Keywords: Conscience paradigm. Intersubjectivity paradigm. Ontological-linguistic turn. Heideggerian existential pre-comprehension. Legal decisions.

Data de recebimento: jan/2011 - Data de aprovação: mar/2011 